Submission ID: 43791

\title{
Modern Approaches to Feasibility Study of Oil and Gas Projects and the Conditions of Cost-Effective Development. The Examples of Versatile Projects Estimations
}

D. Milyaev* (SNIIGGiMS JSC), S. Sukharev (SNIIGGiMS JSC)

\section{SUMMARY}

\begin{abstract}
The geological exploration consistency lies in the successive study of a sedimentary basin, an oil and gas accumulation zone, exploration targets, and than a field. Thus, as the knowledge is being gathered, the studied territory is repeatedly localised, geological approaches and criteria evolve, the exploration maturity improves, the uncertainty level decreases, and principally different management tasks are set.

The economic appraisal, as a constitutive of the elaboration of corporate solutions, shall consider the specifics described. In particular, for two different types of hydrocarbon objects and geological exploration stages, there must be different objectives, tasks, methods, and sought indicators of economic analysis. The authors suggest a conceptual methodological approach to defining feasibility of diverse oil and gas projects and the conditions of cost-effective development, and consider its application on various scales: to a macroregion (southern Siberian Platform), separate highly promising zones within a macroregion (Baikit, Nepa-Botuoba, etc.), prepared and identified structures (Kapaevskaya and Katskaya-2 within the Verkhnekatangsky block), and a developed field.

The authors conclude that feasibility study methods must be applied correctly in terms of methodology.
\end{abstract}


Современные подходы к определению эффективности нефтегазовых проектов и условий рентабельного освоения. Примеры решения разноплановых задач в области оценки проектов.

\section{Д.В. Миляев* (АО "СНИИГГиМС"), С.Б. Сухарев (АО "СНИИГГиМС")}

\section{Введение}

Логика геологоразведочного процесса предполагает последовательное изучение осадочного бассейна, зоны нефтегазонакопления, поисковых объектов и, в дальнейшем, месторождения [1]. Таким образом, в процессе накопления знаний происходит многократная локализация исследуемой территории, трансформируются геологические подходы и критерии, повышается степень изученности, снижается уровень неопределённости, ставятся принципиально отличные управленческие задачи.

Экономическая оценка, как неотъемлемый элемент выработки корпоративных решений, должна учитывать обозначенную специфику. В частности, для разных типов углеводородных объектов и стадий геологического изучения должны существенным образом отличаться цели, задачи, методы и искомые показатели экономического анализа.

\section{Методические принципы геолого-экономического анализа}

Проведённая авторами работа позволяет сформулировать методические принципы геолого-экономического анализа в зависимости от вида и изученности объекта исследования:

1. Изучение осадочного бассейна необходимо ориентировать на сужение потенциально интересной территории до геологически и, что важно, экономически разумных пределов. Следовательно, должны быть определены ограничения при которых возможно рентабельное освоение недр. Для этого авторами рекомендуется экспресс-метод на основе затратного подхода, оперирующий укрупнёнными исходными показателями. Экономическое заключение должно содержать рекомендации по детальному изучению выделенных зон нефтегазонакопления или их частей с указанием целевых горизонтов, типов и крупности ловушек, в которых могут быть открыты рентабельные залежи углеводородов.

2. Исследование зоны нефтегазонакопления, как правило, предшествует приобретению компанией лицензии на право пользования недрами конкретного участка недр. Задача экономистов - обеспечить выбор участка (актива) с наибольшей ожидаемой доходностью и минимальными рисками. Необходимо комплексно оценить потенциал освоения каждого участка нефтегазоносной зоны, а затем провести их сопоставление и ранжирование. Для этого рекомендуется исследование в большей степени качественных и в меньшей степени количественных характеристик потенциальных участков недр на основе сравнительного подхода. Экономическое заключение должно содержать обоснование рекомендуемого к лицензированию участка недр.

3. Рассмотрение поисковых объектов (подготовленных или выявленных структур) направлено на отбор наиболее перспективных из них и определение последовательности (приоритета) бурения скважин. На данном этапе изучения недр геологическая неопределённость остаётся высокой, существует риск понести существенные финансовые потери, если скважина окажется "сухой" $[2,3]$. Поэтому в рамках экономического обоснования должна оцениваться вероятность открытия рентабельной залежи. Для анализа поискового объекта авторами рекомендуется применение вероятностных методов на основе модифицированного доходного подхода. По итогам численных расчётов формируется очерёдность опоискования объектов по принципу приоритета наименее рисковых, а среди них - наиболее доходных.

4. Наконец, когда месторождение открыто, на первый план выходит оптимальность реализуемых вариантов разведки и разработки недр с точки зрения получения не только максимальной добычи, но и максимальной доходности инвестиций. Отличительной особенностью является необходимость максимально полного и достоверного учёта всех тонкостей производственного процесса, которыми можно было пренебречь на более ранних 
этапах освоения углеводородных ресурсов. Для анализа месторождений рекомендуется использование детализированного доходного подхода с проведением многовариантных расчётов и построением на их основе дерева решений. Экономическое заключение должно содержать технико-экономическое обоснование рекомендуемого варианта разведки или работки месторождения.

\section{Примеры решения разноплановых задач}

В 2016 году завершён очередной этап фундаментальной работы АО "СНИИГГиМС": сформирован сейсмический проект общим объёмом порядка 34 тыс. пог. км разрезов с привязкой к 150 наиболее представительным скважинам, на региональном уровне прослежены основные сейсмические горизонты, подготовлен комплект карт и схем, позволяющий осуществлять моделирование процесса развития нефтегазоносного бассейна.

Концептуальный подход к геолого-экономической оценке нефтегазоносного бассейна был реализован авторами на примере юга Сибирской платформы. В процессе упомянутой работы ресурсы нефти, газа и конденсата дифференцировались по нефтегазоносным комплексам, типам флюидов, типам ловушек и классам крупности [4]. Единичным (локальным) объектом оценки принималась типовая прогнозируемая залежь, которая может быть открыта в результате комплекса ГРР и в дальнейшем стать самостоятельным объектом разработки. Таким образом были смоделированы 91 нефтяная и 104 газовые типовые залежи, а общее количество прогнозируемых объектов составило 3360 и 4500 с преобладанием соответственно нефтяной или газовой части.

Геолого-экономическая оценка каждой потенциальной залежи была проведена на авторском автоматизированном комплексе GeoProfi. По полученным данным построена карта плотностей ожидаемого дохода и определены пороговые (критические) значения основных параметров: удалённости от нефте и газопроводов, начального дебита скважин, глубин залегания продуктивных горизонтов, плотности ресурсов, ожидаемой плотности запасов (рисунок 1).
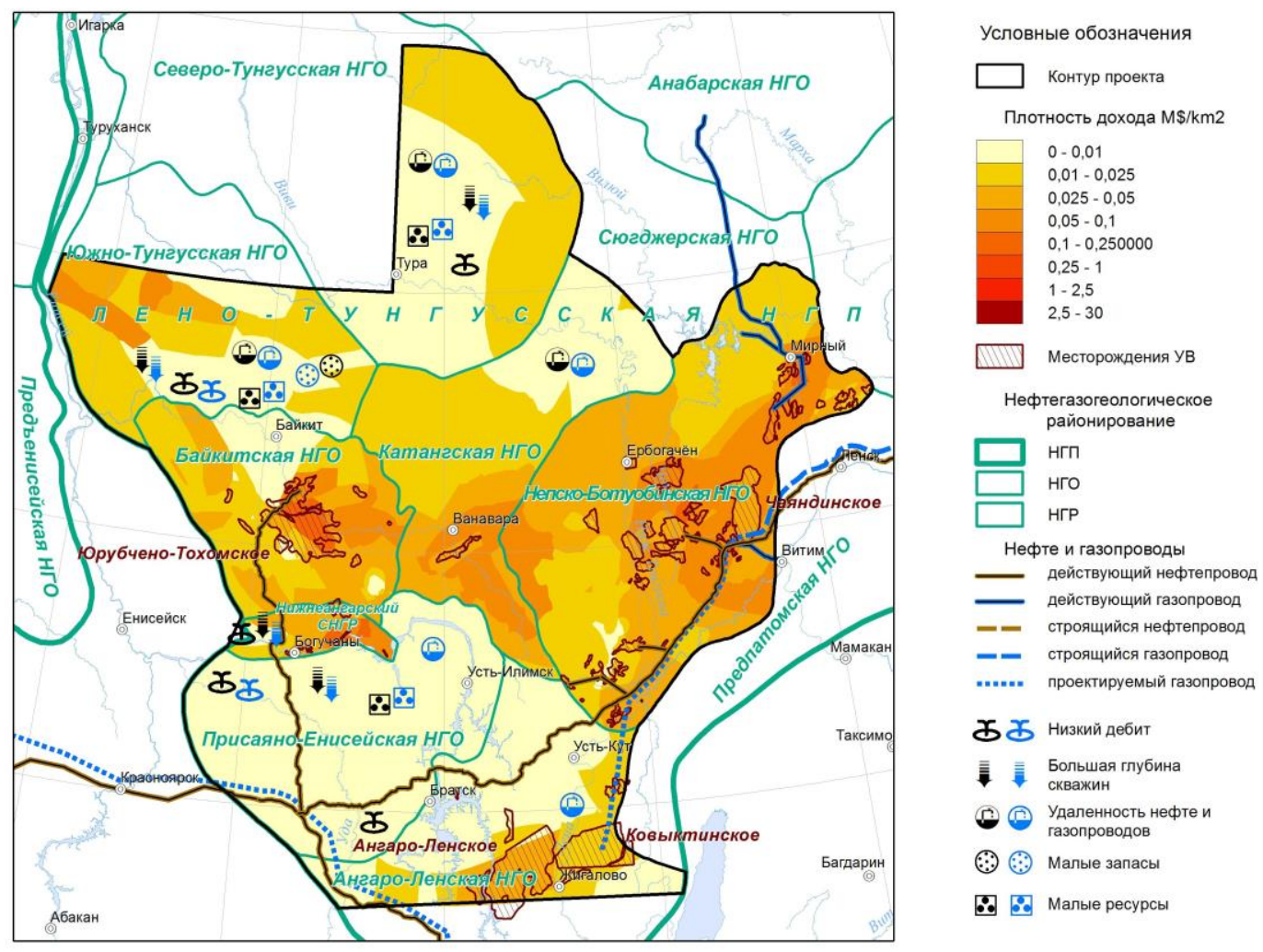

Рисунок 1 Карта плотностей ожидаемого дохода и критических параметров для освоения юга Сибирской платформы (млн долл./км²) 
Проведённая работа позволила выделить перспективные зоны нефтегазонакопления, для которых, в свою очередь, было проведено углубленно исследование согласно описанной выше методике. В качестве результата определены участки наиболее привлекательные для изучения и освоения по совокупности критериев: ресурсный потенциал, распространение продуктивных нефтегазоносных комплексов, результаты проведённых геологоразведочных работ, транспортная инфраструктура, возможность приобретения права пользования, геологоэкономическая оценка.

Для обозначенных участков составлялись электронные паспорта, включающие геофизические и скважинные материалы, с последующим углубленным геологическим и экономическим исследованием и подготовкой технико-экономических предложений по приобретению участков и проведению на них геологоразведочных работ. В сжатом виде эти данные представлены в альбоме "Перспективные лицензионные участки Восточной Сибири и Республики Саха (Якутия)" [5].

Дальнейшее исследование заключалось в рассмотрении перспектив поисковых объектов в пределах отобранных участков недр. Например, для Верхнекатангского участка, расположенного в Иркутской области, геолого-экономический анализ был ориентирован на совокупное рассмотрение залежей Капаевской и Катской-2 структур и определение вероятности их подтверждения (рисунок 2). Проведенное с помощью авторского комплекса GeoProfi исследование позволило смоделировать последовательность опоискования залежей, оценить вероятность получения рентабельного открытия и потенциально возможные финансовые потери.

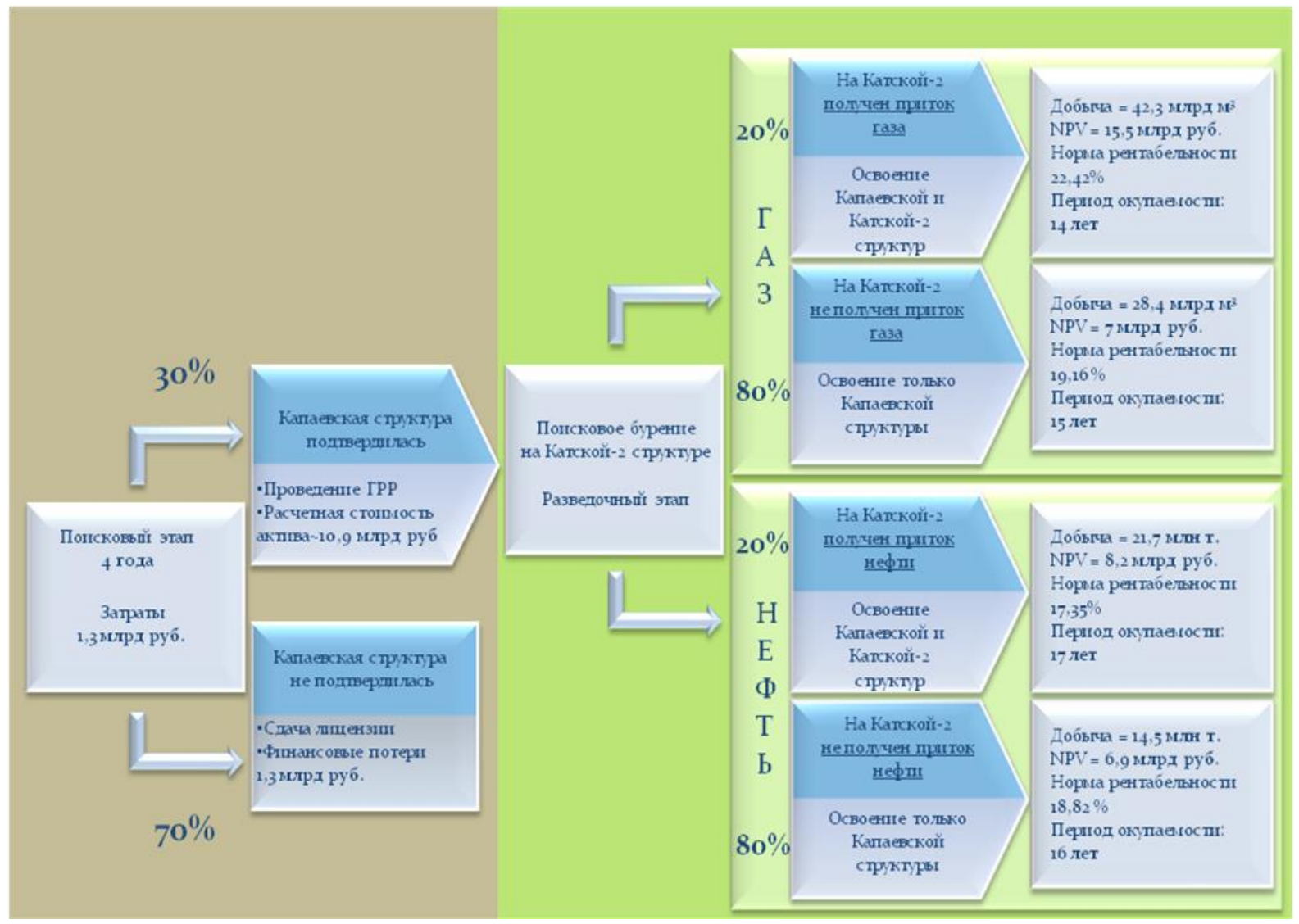

Рисунок 2 Вероятностная геолого-экономическая оценка Верхнекатангсого лицензионного участка 
Задача технико-экономического анализа действующих нефтегазовых месторождений, заключается в оптимизации технологической схемы разработки. Представленный на рисунке 3 пример отражает результат проведённого моделирования профиля добычи (синяя кривая) по сравнению с действующим проектом (зеленая линия). Оптимизированная схема позволяет при сохранении КИН за счёт умеренных затрат повысить темпы извлечения нефти без угрозы для нарушения коллекторских свойств пласта, за счёт этого - на 2,3\% повысить рентабельность разработки месторождения.

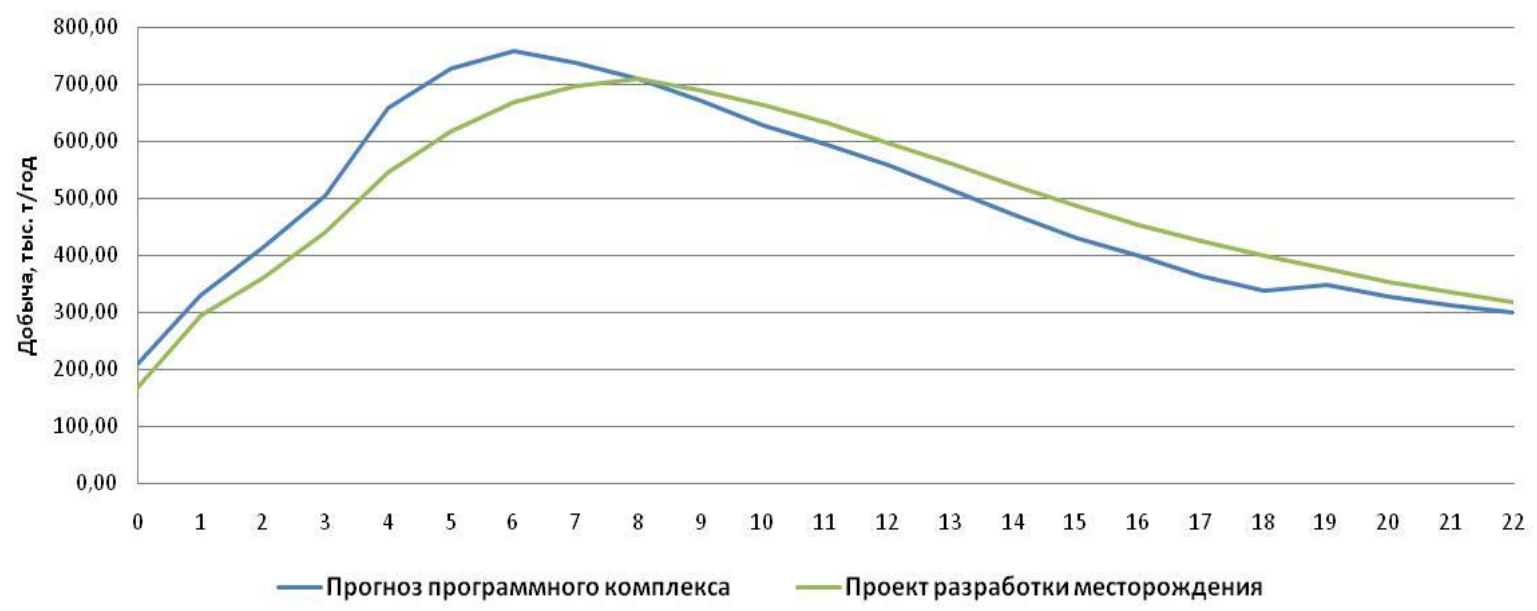

Рисунок 3 Сравнение проектного и оптимизированного прогнозного профилей добычи нефти

\section{Выводы}

Подходы к оценке принципиально отличаются в зависимости от вида и степени изученности анализируемого объекта: осадочного бассейна, зоны нефтегазонакопления, поискового объекта и месторождения. Правильное использование аппарата геологоэкономической оценки позволяет координировать ход геологоразведки и разработки, определяя наиболее эффективные направления работ и минимизируя проектные риски.

\section{Библиография}

1. Лич, Х. Руководство по геологоразведке. ТНК-ВР Холдинг, ON Communication, Москва, 2006, c. $1-218$

2. Ampilov Yu.P. Profitability Evaluation of Subsurface Areas. Geoinformmark Moscow, 2011, p. 1408

3. Ampilov Yu.P., Gert A.A. Economic Geology. Geoinformmark Moscow, 2006, p. 1-329

4. Варламов А.И. и др. Методические рекомендации по геолого-экономической оценке ресурсов нефти, газа и конденсата, Свиньин и сыновья, Новосибирск - Москва, 2015, с. 1-59

5. Миляев Д.В. Перспективные лицензионные участки Восточной Сибири и Республики Саха (Якутия), Allprint, Новосибирск, 2017, с. 1-203

\section{References}

1. Leach H. Exploration Technical Handbook. TNK-BP, ON Communication, Moscow, 2006, p. 1218 


\section{EAGE}

2. Ampilov Yu.P. Profitability Evaluation of Subsurface Areas. Geoinformmark Moscow, 2011, p. 1408

3. Ampilov Yu.P., Gert A.A. Economic Geology. Geoinformmark Moscow, 2006, p. 1-329

4. Varlamov A. I., etc. Methodological recommendations for geological and economic evaluation of oil, gas and condensate. Svinyin and sons, Novosibirsk - Moscow, 2015, p. 1-59

5. Milyaev D.V. Promising licensed blocks in Eastern Siberia and Sakha (Yakutia) Republic, Allprint, Novosibirsk, 2017, p. 1-203 